\title{
Prevalence of tobacco use in urban and rural areas of Pakistan; a sub-study from second National Diabetes Survey of Pakistan (NDSP) 2016 - 2017
}

\author{
Abdul Basit ${ }^{1}$, Bilal Bin Younus ${ }^{2}$, Nazish Waris ${ }^{3}$, \\ Asher Fawwad ${ }^{4}$, NDSP members*
}

\begin{abstract}
Objective: To assess age standardized prevalence of tobacco use in urban and rural areas of Pakistan.

Methods: This is a sub-study of second National Diabetes Survey of Pakistan (NDSP) 2016-2017. Prevalence of tobacco, ex-tobacco and non-tobacco users was determined in urban/rural areas of four provinces (Punjab, Sindh, Khyber Pakhtunkhwa, and Baluchistan) of Pakistan amongst people aged greater than or equal to 20 years. Information regarding tobacco and non-tobacco users were obtained from second NDSP (2016-2017) predesigned questionnaire. Detailed methodology for demographic, anthropometric and biochemical parameters remained same as reported in second NDSP (2016-2017).

Results: The age-standardized prevalence of tobacco use in Pakistan was found to be $13.4 \%$. Tobacco use in urban areas was $16.3 \%$ and rural areas was $11.7 \%$. Tobacco use in urban and rural males was $26.1 \%$ and $24.1 \%$, while in females was $7.7 \%$ and $3.1 \%$, respectively. The age-standardized prevalence of ex-tobacco use in Pakistan was found to be $2.3 \%$. Ex-tobacco use in urban areas was $2.6 \%$ and rural areas was $2.3 \%$. Similarly, ex-tobacco use in urban and rural males was $4.6 \%$ and $4.6 \%$, while in females was $0.7 \%$ and $0.5 \%$, respectively. Multinomial logistic regression analysis shows that increasing age does not relate towards addiction of tobacco. Males were found to be 7 times (OR 6.94, 95\% $\mathrm{Cl} 5.68-8.49$ ) and urban residents twice (OR 2.09, 95\% $\mathrm{Cl} 1.73-2.52$ ) more tobacco users than females and those living in rural areas, respectively. From the likelihood ratio test, all variables were found to be statistically significant except for dysglycemia, dyslipidemia and hypertension.

Conclusion: The prevalence of tobacco use is high. As a sub paper of a large national survey, this evidence is expected to serve as an important tool to plan larger studies leading in turn to develop strategies for a successful tobacco control program in the country.
\end{abstract}

KEYWORDS: age standardization, standardized prevalence, second NDSP, tobacco, Type-II diabetes.

How to cite this:

doi: https://doi.org/10.12669/pjms.36.4.1705

Basit A, Younus BB, Waris N, Fawwad A, NDSP members. Prevalence of tobacco use in urban and rural areas of Pakistan; a sub-study from second National Diabetes Survey of Pakistan (NDSP) 2016 - 2017. Pak J Med Sci. 2020;36(4):808-815. doi: https://doi.org/10.12669/pjms.36.4.1705

This is an Open Access article distributed under the terms of the Creative Commons Attribution License (http://creativecommons.org/licenses/by/3.0), which permits unrestricted use, distribution, and reproduction in any medium, provided the original work is properly cited.

Correspondence:

Prof. Abdul Basit, FRCP.

Professor of Medicine, Baqai Medical University,

Director, Baqai Institute of Diabetology and Endocrinology,

Baqai Medical University,

Plot No. 1-2, II-B, Nazimabad No. 2,

Karachi-74600, Pakistan.

Email: abdulbasit@bide.edu.pk research@bide.edu.pk

* Received for Publication:

September 25, 2019

* Revision Received:

* Revision Accepted:

\section{INTRODUCTION}

Tobacco use jeopardizes human health and is one of the major sources for non-communicable diseases including chronic obstructive pulmonary diseases (COPD), cardiovascular diseases, diabetes and cancers. ${ }^{1}$ Tobacco related diseases are a major cause and consequence of poverty in low- and middle-income countries (LMICs). ${ }^{2}$

Globally, 942 million men and 175 million women ages 15 or older smoke tobacco. ${ }^{3}$ It is 
responsible for death of about seven million people each year; many are premature deaths reported by World Health Organization's (WHO) new Global Report on Trends in Prevalence of Tobacco Smoking 2000-2025. ${ }^{4}$ However, in developed countries a decline in the prevalence of tobacco use has been reported. Unfortunately, on the contrary, there is increase of tobacco consumption in LMICs. Almost $80 \%$ of the world's smokers live in LMICs and Pakistan is also no exception. ${ }^{5}$ In a recent study, overall prevalence of tobacco use in Pakistan are found less common compared to its neighboring countries $(19.1 \%$ vs. $>25 \%)^{6}$

Generally, use of tobacco start around adolescence. ${ }^{7}$ In developing countries, more than half of the adolescents start smoking at an early age and become regular tobacco users subsequently. ${ }^{8}$ Male gender, old age, less education, high coffee or tea consumption, sharing a household with smoker are the most common risk factors for using tobacco. ${ }^{9}$ Tobacco use not only produce various social, cultural, biomedical, economic, and geopolitical problems, but it is also considered to be the key preventable risk factor for morbidity and mortality. ${ }^{2}$

Tobacco control should be a top priority in health issues as well as for reduction of poverty. The Government of Pakistan (GoP) is signatory to the World Health Organization (WHO) and Framework Convention on Tobacco Control (FCTC) that employs six effective strategies and also has also taken a number of initiatives regarding the creation of Tobacco Control Cell at Federal level and health related issues. ${ }^{6,10,11}$ However, there is a dearth of information on the prevalence, determinants, and management of tobacco use in Pakistan apart from the Global Adult Tobacco Survey (GATS) $2014 .{ }^{6}$ Therefore, this sub-study aimed to assess the age standardized prevalence of tobacco use in urban and rural areas of four provinces of Pakistan amongst people aged 20 years or more.

\section{METHODS}

Data for this sub-study of the primary study was obtained from second National Diabetes Survey of Pakistan (NDSP) 2016-2017, a large, communitybased epidemiological survey. ${ }^{12}$ The duration of survey was over 19 months (February 2016 and August 2017). Ethical approval was obtained from the National Bioethics Committee (NBC) of Pakistan (Ref: No.4-87/17/NBC-226/NBC/2664, dated January 31, 2017). Written informed consent was obtained from all participants in their local languages.

The main objective of the survey was to assess the prevalence of Type-II diabetes mellitus (T2DM) and its associated risk factors in urban and rural areas of all four provinces of Pakistan that includes Punjab, Sindh, Khyber Pakhtunkhwa (KPK) and Baluchistan (as defined in latest available census). ${ }^{12}$ Detailed methodology regarding sample size, age standardization, demographic, anthropometric measurements and biochemical analysis were same as in second NDSP (2016-2017). ${ }^{12}$

Information regarding tobacco, ex-tobacco and non-tobacco users for current study were also obtained from the second NDSP (20162017) questionnaire. It is a non-comprehensive questionnaire for tobacco assessment as it was mainly designed for the assessment of diabetes. Participants currently using any form of tobacco, irrespective of duration and quantity consumed were called tobacco users, ex-tobacco users as having used tobacco in the past, but not since last month and participants who have never used any form of tobacco were known as non-tobacco users. ${ }^{12,13}$ The term tobacco used in our study was defined as the alkaloid nicotine containing compounds mainly used for smoking in manufactured cigarettes, cigars, water pipe (hookah/shisha) and smokeless tobacco (chewing tobacco in the form of paan, gutka, naswar and dipping tobacco) ${ }^{14}$

Statistical analysis: Statistical analysis were performed using statistical package for social sciences (SPSS Version 22). Estimates were expressed as mean $\pm S D$. Student's t-test were used to compare groups for continuous variables and Chi square test was used to compare proportions between the two groups. Multiple logistic regression analysis was used to examine the association between outcome variable "tobacco and ex-tobacco users" and various factors like age, gender, place of residence, marital status, education, physical activity, obesity, diabetes, hypertension and dyslipidemia. Using backward selection, variables that remained significant were retained in the final model. $\mathrm{P}<0.05$ was considered statistically significant.

\section{RESULTS}

In second NDSP (2016-2017) survey, 10834 individuals were screened for diabetes fulfilling inclusion criteria. In this sub-study, data regarding tobacco use was available for $9520(87.9 \%)$ participants. The age-standardized prevalence of 
Prevalence of tobacco use in Pakistan

Table-I: Baseline and biochemical characteristics of the study participants.

\begin{tabular}{|c|c|c|c|c|c|c|c|c|c|c|}
\hline \multirow{2}{*}{ Variables } & & \multicolumn{3}{|c|}{ Urban } & \multicolumn{3}{|c|}{ Rural } & \multicolumn{3}{|c|}{ Overall } \\
\hline & & Tobacco user & $\begin{array}{c}\text { Ex-tobacco } \\
\text { user }\end{array}$ & $\begin{array}{c}\text { Non- } \\
\text { tobacco } \\
\text { user }\end{array}$ & $\begin{array}{c}\text { Tobacco } \\
\text { user }\end{array}$ & $\begin{array}{c}\text { Ex-tobacco } \\
\text { user }\end{array}$ & $\begin{array}{c}\text { Non-tobacco } \\
\text { user }\end{array}$ & $\begin{array}{c}\text { Tobacco } \\
\text { user }\end{array}$ & $\begin{array}{c}\text { Ex- } \\
\text { tobacco } \\
\text { user }\end{array}$ & $\begin{array}{c}\text { Non- } \\
\text { tobacco } \\
\text { user }\end{array}$ \\
\hline $\mathrm{N}$ & & 592 & 114 & 2722 & 784 & 163 & 5145 & 1376 & 277 & 7867 \\
\hline Age (years) & & $46.2 \pm 13.4$ & $49.9 \pm 13.5^{*}$ & $43.0 \pm 13.7$ & $48.6 \pm 14.7$ & $50.7 \pm 13.2^{*}$ & $42.8 \pm 13.9$ & $47.6 \pm 14.2$ & $\begin{array}{l}50.4 \pm \\
13.3^{*}\end{array}$ & $\begin{array}{l}42.9 \pm \\
13.9\end{array}$ \\
\hline \multirow{2}{*}{ Gender } & Male & $444(26.6 \%)$ & $98(5.9 \%)^{*}$ & $\begin{array}{c}1129 \\
(67.6 \%)\end{array}$ & $\begin{array}{c}645 \\
(25.6 \%)\end{array}$ & $\begin{array}{c}139 \\
(5.5 \%)^{*}\end{array}$ & $\begin{array}{c}1732 \\
(68.8 \%)\end{array}$ & $\begin{array}{l}1089 \\
(26 \%)\end{array}$ & $\begin{array}{c}237 \\
(5.7 \%)^{*}\end{array}$ & $\begin{array}{c}2861 \\
(68.3 \%)\end{array}$ \\
\hline & Female & $148(8.4 \%)$ & $16(0.9 \%)^{*}$ & $\begin{array}{c}1593 \\
(90.7 \%)\end{array}$ & $\begin{array}{c}139 \\
(3.9 \%)\end{array}$ & $24(0.7 \%)^{*}$ & $\begin{array}{c}3413 \\
(95.4 \%)\end{array}$ & $\begin{array}{c}287 \\
(5.4 \%)\end{array}$ & $\begin{array}{c}40 \\
(0.8 \%)^{*}\end{array}$ & $\begin{array}{c}5006 \\
(93.9 \%)\end{array}$ \\
\hline \multirow{4}{*}{ Province } & Punjab & $168(10 \%)$ & $27(1.6 \%)^{*}$ & $\begin{array}{c}1478 \\
(88.3 \%)\end{array}$ & $\begin{array}{c}446 \\
(11.8 \%)\end{array}$ & $71(1.9 \%)^{*}$ & $\begin{array}{c}3273 \\
(86.4 \%)\end{array}$ & $\begin{array}{c}614 \\
(11.2 \%)\end{array}$ & $\begin{array}{c}98 \\
(1.8 \%)^{*}\end{array}$ & $\begin{array}{c}4751 \\
(87 \%)\end{array}$ \\
\hline & Sindh & $306(24.3 \%)$ & $20(1.6 \%)^{*}$ & $\begin{array}{c}931 \\
(74.1 \%)\end{array}$ & $\begin{array}{c}187 \\
(19.3 \%)\end{array}$ & $20(2.1 \%)^{*}$ & $\begin{array}{c}761 \\
(78.6 \%)\end{array}$ & $\begin{array}{c}493 \\
(22.2 \%)\end{array}$ & $\begin{array}{c}40( \\
1.8 \%)^{*}\end{array}$ & $\begin{array}{c}1692 \\
(76 \%)\end{array}$ \\
\hline & KPK & $57(17.9 \%)$ & $50(15.7 \%)^{*}$ & $\begin{array}{c}212 \\
(66.5 \%)\end{array}$ & $60(6.1 \%)$ & $49(4.9 \%)^{*}$ & $882(89 \%)$ & $\begin{array}{c}117 \\
(8.9 \%)\end{array}$ & $\begin{array}{c}99 \\
(7.6 \%)^{*}\end{array}$ & $\begin{array}{c}1094 \\
(83.5 \%)\end{array}$ \\
\hline & $\begin{array}{l}\text { Baluc- } \\
\text { histan }\end{array}$ & $61(34.1 \%)$ & $17(9.5 \%)^{*}$ & $\begin{array}{c}101 \\
(56.4 \%)\end{array}$ & $\begin{array}{c}91 \\
(26.5 \%)\end{array}$ & $23(6.7 \%)^{*}$ & $\begin{array}{c}229 \\
(66.8 \%)\end{array}$ & $\begin{array}{c}152 \\
(29.1 \%)\end{array}$ & $\begin{array}{c}40 \\
(7.7 \%)^{*}\end{array}$ & $\begin{array}{c}330 \\
(63.2 \%)\end{array}$ \\
\hline \multirow{2}{*}{ Marital status } & Single & $51(10.8 \%)$ & $8(1.7 \%)^{*}$ & $\begin{array}{c}415 \\
(87.6 \%)\end{array}$ & $83(8.6 \%)$ & $16(1.7 \%)^{*}$ & $\begin{array}{c}869 \\
(89.8 \%)\end{array}$ & $\begin{array}{c}134 \\
(9.3 \%)\end{array}$ & $\begin{array}{c}24 \\
(1.7 \%)^{*}\end{array}$ & $\begin{array}{c}1284 \\
(89 \%)\end{array}$ \\
\hline & Married & $534(18.6 \%)$ & $\begin{array}{c}105 \\
(3.7 \%)^{*}\end{array}$ & $\begin{array}{c}2228 \\
(77.7 \%)\end{array}$ & $\begin{array}{c}681 \\
(13.7 \%)\end{array}$ & $\begin{array}{c}146 \\
(2.9 \%)^{*}\end{array}$ & $\begin{array}{c}4146 \\
(83.4 \%)\end{array}$ & $\begin{array}{c}1215 \\
(15.5 \%)\end{array}$ & $\begin{array}{c}251 \\
(3.2 \%)^{*}\end{array}$ & $\begin{array}{c}6374 \\
(81.3 \%)\end{array}$ \\
\hline \multicolumn{2}{|c|}{$\begin{array}{l}\text { Body Mass Index (kg/ } \\
\left.\mathrm{m}^{\wedge} 2\right)\end{array}$} & $26.4 \pm 5.4$ & $26.7 \pm 4.2^{*}$ & $27.1 \pm 5.8$ & $26.3 \pm 5.5$ & $26.5 \pm 4.5^{*}$ & $27.4 \pm 6.3$ & $26.4 \pm 5.5$ & $\begin{array}{c}26.6 \pm \\
4.4^{*}\end{array}$ & $27.3 \pm 6.1$ \\
\hline WHR & & $0.94 \pm 0.1$ & $0.96 \pm 0.16$ & $0.94 \pm 0.14$ & $0.91 \pm 0.09$ & $0.92 \pm 0.1^{*}$ & $0.96 \pm 0.24$ & $0.93 \pm 0.1$ & $\begin{array}{c}0.95 \pm \\
0.15\end{array}$ & $\begin{array}{c}0.95 \pm \\
0.19\end{array}$ \\
\hline \multirow{2}{*}{$\begin{array}{l}\text { Education } \\
\text { level }\end{array}$} & $\begin{array}{l}\text { Less } \\
\text { than } \\
\text { primary }\end{array}$ & $176(20.4 \%)$ & $19(2.2 \%)$ & $\begin{array}{c}668 \\
(77.4 \%)\end{array}$ & $\begin{array}{c}455 \\
(13.2 \%)\end{array}$ & $76(2.2 \%)^{*}$ & $\begin{array}{c}2913 \\
(84.6 \%)\end{array}$ & $\begin{array}{c}631 \\
(14.7 \%)\end{array}$ & $\begin{array}{c}95 \\
(2.2 \%)^{*}\end{array}$ & $\begin{array}{c}3581 \\
(83.1 \%)\end{array}$ \\
\hline & $\begin{array}{l}\text { Primary } \\
\text { or more }\end{array}$ & $401(16.2 \%)$ & $92(3.7 \%)$ & $\begin{array}{c}1986 \\
(80.1 \%)\end{array}$ & $\begin{array}{c}298 \\
(12.3 \%)\end{array}$ & $85(3.5 \%)^{*}$ & $\begin{array}{c}2046 \\
(84.2 \%)\end{array}$ & $\begin{array}{c}699 \\
(14.2 \%)\end{array}$ & $\begin{array}{c}177 \\
(3.6 \%)^{*}\end{array}$ & $\begin{array}{c}4032 \\
(82.2 \%)\end{array}$ \\
\hline \multirow{2}{*}{$\begin{array}{l}\text { Physical } \\
\text { activity }\end{array}$} & No & $420(16.1 \%)$ & $76(2.9 \%)$ & $\begin{array}{l}2107 \\
(80.9 \%)\end{array}$ & $\begin{array}{c}482 \\
(10.6 \%)\end{array}$ & $116(2.6 \%)$ & $\begin{array}{c}3945 \\
(86.8 \%)\end{array}$ & $\begin{array}{c}902 \\
(12.6 \%)\end{array}$ & $\begin{array}{c}192 \\
(2.7 \%)\end{array}$ & $\begin{array}{c}6052 \\
(84.7 \%)\end{array}$ \\
\hline & Yes & $74(18.6 \%)$ & $15(3.8 \%)$ & $\begin{array}{c}309 \\
(77.6 \%)\end{array}$ & $\begin{array}{c}188 \\
(18.6 \%)\end{array}$ & $20(2 \%)^{*}$ & $\begin{array}{c}803 \\
(79.4 \%)\end{array}$ & $\begin{array}{c}262 \\
(18.6 \%)\end{array}$ & $\begin{array}{c}35 \\
(2.5 \%)^{*}\end{array}$ & $\begin{array}{c}1112 \\
(78.9 \%)\end{array}$ \\
\hline \multirow{2}{*}{$\begin{array}{l}\text { Alcohol } \\
\text { addiction }\end{array}$} & No & $466(14.9 \%)$ & $101(3.2 \%)$ & $\begin{array}{c}2564 \\
(81.9 \%)\end{array}$ & $\begin{array}{c}607 \\
(10.4 \%)\end{array}$ & $135(2.3 \%)$ & $\begin{array}{c}5082 \\
(87.3 \%)\end{array}$ & $\begin{array}{l}1073 \\
(12 \%)\end{array}$ & $\begin{array}{c}236 \\
(2.6 \%)\end{array}$ & $\begin{array}{c}7646 \\
(85.4 \%)\end{array}$ \\
\hline & Yes & $27(84.4 \%)$ & $2(6.2 \%)$ & $3(9.4 \%)^{*}$ & $96(80 \%)$ & $8(6.7 \%)^{*}$ & $16(13.3 \%)$ & $\begin{array}{c}123 \\
(80.9 \%)\end{array}$ & $\begin{array}{c}10 \\
(6.6 \%)^{*}\end{array}$ & $\begin{array}{c}19 \\
(12.5 \%)\end{array}$ \\
\hline \multirow{2}{*}{ Obesity } & No & $234(19.7 \%)$ & $39(3.3 \%)$ & $\begin{array}{c}914 \\
(77 \%)\end{array}$ & $\begin{array}{c}274 \\
(14.2 \%)\end{array}$ & $53(2.7 \%)$ & $\begin{array}{c}1603 \\
(83.1 \%)\end{array}$ & $\begin{array}{c}508 \\
(16.3 \%)\end{array}$ & $92(3 \%)$ & $\begin{array}{c}2517 \\
(80.8 \%)\end{array}$ \\
\hline & Yes & $310(16.5 \%)$ & $69(3.7 \%)$ & $\begin{array}{c}1496 \\
(79.8 \%)\end{array}$ & $\begin{array}{c}401 \\
(12.9 \%)\end{array}$ & $94(3 \%)$ & $\begin{array}{c}2606 \\
(84 \%)\end{array}$ & $\begin{array}{c}711 \\
(14.3 \%)\end{array}$ & $\begin{array}{c}163 \\
(3.3 \%)^{*}\end{array}$ & $\begin{array}{c}4102 \\
(82.4 \%)\end{array}$ \\
\hline \multirow{2}{*}{ Dysglycemia } & No & $365(16.8 \%)$ & $78(3.6 \%)$ & $\begin{array}{c}1735 \\
(79.7 \%)\end{array}$ & $\begin{array}{c}531 \\
(12.7 \%)\end{array}$ & $103(2.5 \%)$ & $\begin{array}{c}3531 \\
(84.8 \%)\end{array}$ & $\begin{array}{c}896 \\
(14.1 \%)\end{array}$ & $\begin{array}{c}181 \\
(2.9 \%)\end{array}$ & $\begin{array}{c}5266 \\
(83 \%)\end{array}$ \\
\hline & Yes & $227(18.2 \%)$ & $36(2.9 \%)$ & $\begin{array}{c}987 \\
(79 \%)\end{array}$ & $\begin{array}{c}253 \\
(13.1 \%)\end{array}$ & $60(3.1 \%)$ & $\begin{array}{c}1614 \\
(83.8 \%)\end{array}$ & $\begin{array}{c}480 \\
(15.1 \%)\end{array}$ & $\begin{array}{c}96 \\
(3 \%)^{*}\end{array}$ & $\begin{array}{c}2601 \\
(81.9 \%)\end{array}$ \\
\hline \multirow{2}{*}{ Hypertension } & No & $285(18.5 \%)$ & $49(3.2 \%)$ & $\begin{array}{c}1210 \\
(78.4 \%)\end{array}$ & $\begin{array}{c}359 \\
(12.8 \%)\end{array}$ & $57(2 \%)$ & $\begin{array}{c}2380 \\
(85.1 \%)\end{array}$ & $\begin{array}{c}644 \\
(14.8 \%)\end{array}$ & $\begin{array}{c}106 \\
(2.4 \%)\end{array}$ & $\begin{array}{c}3590 \\
(82.7 \%)\end{array}$ \\
\hline & Yes & $300(17.1 \%)$ & $60(3.4 \%)$ & $\begin{array}{c}1395 \\
(79.5 \%)\end{array}$ & $\begin{array}{c}388 \\
(12.7 \%)\end{array}$ & $100(3.3 \%)^{*}$ & $\begin{array}{c}2565 \\
(84 \%)\end{array}$ & $\begin{array}{c}688 \\
(14.3 \%)\end{array}$ & $\begin{array}{c}160 \\
(3.3 \%)^{*}\end{array}$ & $\begin{array}{c}3960 \\
(82.4 \%)\end{array}$ \\
\hline \multirow{2}{*}{ Dyslipidemia } & No & $17(23 \%)$ & $2(2.7 \%)$ & $\begin{array}{c}55 \\
(74.3 \%)\end{array}$ & $\begin{array}{c}32 \\
(18.8 \%)\end{array}$ & $6(3.5 \%)$ & $\begin{array}{c}132 \\
(77.6 \%)\end{array}$ & $\begin{array}{c}49 \\
(20.1 \%)\end{array}$ & $\begin{array}{c}8 \\
(3.3 \%)\end{array}$ & $\begin{array}{c}187 \\
(76.6 \%)\end{array}$ \\
\hline & Yes & $457(17.7 \%)$ & $51(2 \%)$ & $\begin{array}{c}2074 \\
(80.3 \%)\end{array}$ & $\begin{array}{c}524 \\
(12.4 \%)\end{array}$ & $89(2.1 \%)^{*}$ & $\begin{array}{c}3620 \\
(85.5 \%)\end{array}$ & $\begin{array}{c}981 \\
(14.4 \%)\end{array}$ & $\begin{array}{c}140 \\
(2.1 \%)^{*}\end{array}$ & $\begin{array}{c}5694 \\
(83.6 \%)\end{array}$ \\
\hline
\end{tabular}

Data presented as mean \pm standard deviation (SD) or $\mathrm{n}(\%)$, Obesity: $\mathrm{BMI} \geq 25 \mathrm{~kg} / \mathrm{m} 2$

* denotes statistically significant difference at $\mathrm{p}$-value $<0.05$ among non-tobacco users, ex-tobacco users and current tobacco users. 
tobacco use in Pakistan was found to be $13.4 \%$. Tobacco use in urban areas was $16.3 \%$ and rural areas was $11.7 \%$. Tobacco use in urban and rural males was $26.1 \%$ and $24.1 \%$, while in females was $7.7 \%$ and $3.1 \%$, respectively. The age-standardized prevalence of ex-tobacco use in Pakistan was found to be $2.3 \%$. Ex-tobacco use in urban areas was $2.6 \%$ and rural areas was $2.3 \%$. Similarly, ex-tobacco use in urban and rural males was $4.6 \%$ and $4.6 \%$, while in females was $0.7 \%$ and $0.5 \%$, respectively.

Mean age (years) of tobacco users, ex-tobacco users and non-tobacco users was 46.2 \pm 13.4 , $49.9 \pm 13.5$ and $43.0 \pm 13.7$, respectively in urban areas and $48.6 \pm 14.7,50.7 \pm 13.2$ and $42.8 \pm 13.9$, in rural areas. Overall, prevalence of tobacco use was higher in province of Baluchistan (34.1\%) and $(26.5 \%)$ followed by Sindh $(24.3 \%)$ and $(19.3 \%)$ in both urban and rural areas, respectively, while exusers were mostly observed in KPK $(15.7 \%)$ in urban areas and Baluchistan (6.7\%) in rural areas. Obesity, hypertension, dysglycemia and dyslipidemia was observed less prevalent in tobacco and ex-tobacco users compared to non-tobacco users (Table-I).

Fig.1 (a-d) shows age-standardized prevalence of tobacco use. In Punjab, rural populations had significantly higher prevalence than urbans in age group $\geq 60$ years, while non-significant difference was observed for ex-tobacco users between all age groups (Fig.1(A)). In Sindh, urban had significantly higher prevalence than rural between $40-49$ years, while, in ex-tobacco users this trend was higher in rural population between 50-59 years (Fig.1(B)). Urban population of KPK had significantly higher prevalence of tobacco users and ex-tobacco users between 30-59 years and $\geq 40$ years of all age groups, respectively (Fig.1(C)). In Baluchistan, significant results were only observed for urban ex-tobacco users than rural between 30-39 years of age group (Fig.1(D)).

The multinomial logistic regression analysis to assess the association of common and biochemical risk factors associated with tobacco use is shown in Table-II. The OR $(95 \% \mathrm{CI})$ show that increasing age does not relate towards tobacco use. Males were about seven times more tobacco users than females. Similarly, urban residents about twice more than rural and people having less than primary education about twice more than people having primary education or more were tobacco users. Participants who were about physically

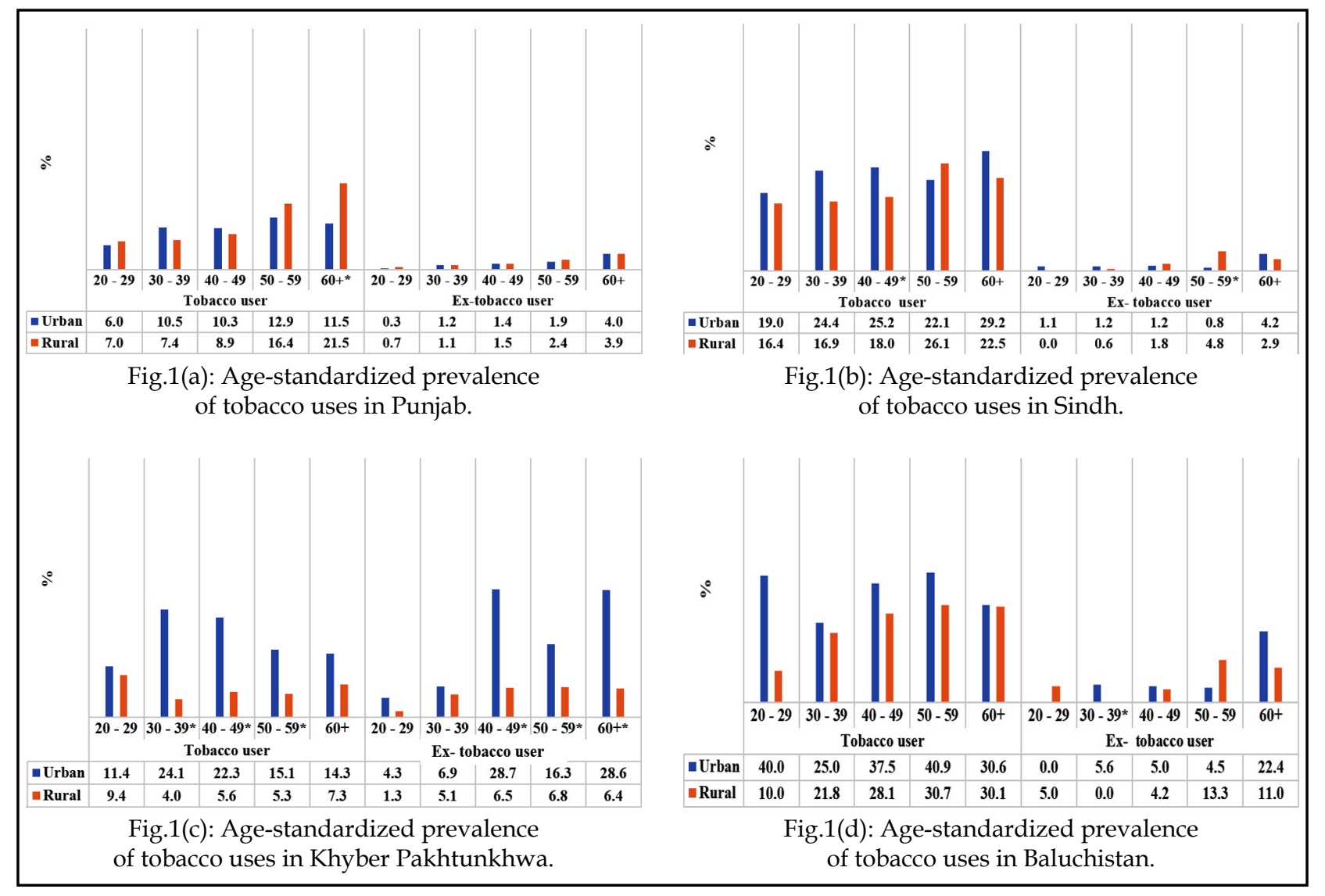


Table-II: Odd ratios of univariate and multivariate analysis to assess the association of tobacco use and its associated factors.

\begin{tabular}{|c|c|c|c|c|c|}
\hline \multirow{2}{*}{ Factors } & & \multicolumn{2}{|c|}{ Tobacco users } & \multicolumn{2}{|c|}{ Ex-tobacco users } \\
\hline & & OR $(95 \%$ C.I $)$ & P-value & OR $(95 \%$ C.I $)$ & P-value \\
\hline \multirow{5}{*}{ Age } & $20-29$ & $0.71(0.49-1.03)$ & 0.072 & $0.19(0.07-0.52)$ & 0.001 \\
\hline & $30-39$ & $0.7(0.52-0.94)$ & .017 & $0.4(0.2-0.79)$ & 0.009 \\
\hline & $40-49$ & $0.83(0.64-1.08)$ & 0.162 & $0.58(0.33-1.02)$ & 0.059 \\
\hline & $50-59$ & $1.3(1-1.69)$ & 0.047 & $0.54(0.28-1.03)$ & 0.061 \\
\hline & $60+$ & 1 & & 1 & \\
\hline \multirow{2}{*}{ Gender } & Male & $6.94(5.68-8.49)$ & \multirow{2}{*}{$<0.0001$} & $10.32(5.87-18.13)$ & \multirow{2}{*}{$<0.0001$} \\
\hline & Female & 1 & & 1 & \\
\hline \multirow{2}{*}{ Place of Orientation } & Urban & $2.09(1.73-2.52)$ & \multirow{2}{*}{$<0.0001$} & $1.07(0.65-1.74)$ & \multirow{2}{*}{0.793} \\
\hline & Rural & 1 & & 1 & \\
\hline \multirow{2}{*}{ Marital status } & Single & $0.75(0.53-1.06)$ & \multirow{2}{*}{0.1} & $1.91(0.93-3.9)$ & \multirow{2}{*}{0.077} \\
\hline & Married & 1 & & 1 & \\
\hline \multirow{2}{*}{ Education } & Less than primary & $2.28(1.88-2.78)$ & \multirow{2}{*}{$<0.0001$} & $2.13(1.32-3.44)$ & \multirow{2}{*}{0.002} \\
\hline & Primary or more & 1 & & 1 & \\
\hline \multirow{2}{*}{$\begin{array}{l}\text { Activity above } \\
\text { average }\end{array}$} & No & $0.66(0.53-0.82)$ & \multirow{2}{*}{$<0.0001$} & $0.76(0.45-1.29)$ & \multirow{2}{*}{0.312} \\
\hline & Yes & 1 & & 1 & \\
\hline \multirow{2}{*}{ Obesity WHO } & No & $1(0.83-1.2)$ & \multirow{2}{*}{0.975} & $0.53(0.33-0.87)$ & \multirow{2}{*}{0.012} \\
\hline & Yes & 1 & & 1 & \\
\hline \multirow{2}{*}{ Dysglycemia } & No & $1.01(0.84-1.22)$ & \multirow{2}{*}{0.915} & $1.15(0.73-1.83)$ & \multirow{2}{*}{0.539} \\
\hline & Yes & 1 & & 1 & \\
\hline \multirow{2}{*}{ Dyslipidemia } & No & $1.32(0.85-2.07)$ & \multirow{2}{*}{0.22} & $1.56(0.6-4.08)$ & \multirow{2}{*}{0.363} \\
\hline & Yes & 1 & & 1 & \\
\hline \multirow{2}{*}{ Hypertension } & No & $1.09(0.9-1.31)$ & \multirow{2}{*}{0.383} & $1.06(0.67-1.68)$ & \multirow{2}{*}{0.798} \\
\hline & Yes & 1 & & 1 & \\
\hline
\end{tabular}

P-value $<0.05$ considered to be statistically significant.

less active were found to consume less tobacco. On the other side, significant association was observed with increasing age and ex-tobacco consumption. Males were found to be about 10 times more likely to be an ex- tobacco user than females, married people about twice than single and people having less than primary education 2 times compared to those having education more than primary. From the likelihood ratio test, all variables were found to be statistically significant except for dysglycemia, dyslipidemia and hypertension.

\section{DISCUSSION}

This sub-study of nationally representative survey second NDSP (2016-2017) provided the current prevalence of tobacco, ex-tobacco uses and its distribution among adults aged $\geq 20$ years in Pakistan. A key finding of our study indicates the age-standardized prevalence of tobacco and ex-tobacco consumption to be $13.4 \%$ and $2.3 \%$, respectively. It shows the declining trend in prevalence of tobacco consumption compared to first national survey in adults GATS- $2014^{6}$ as 
well as South-East Asia regions or neighboring countries including Bangladesh and India. ${ }^{15}$ Meanwhile, our results are comparable to Rwanda $(12.8 \%)$, Tanzania $(14.1 \%)$, Kenya $(13.5 \%)$ and some other countries. ${ }^{16}$ In Pakistan, variation of tobacco use at orientation and provincial levels was also observed as it was more prevalent in urban population of Baluchistan followed by Sindh and KPK and rural areas of Punjab.

Various studies have shown high prevalence of tobacco consumption in older age and male gender which support our findings. ${ }^{17-20}$ In our study, marked gender difference of tobacco consumption was similar to previous study. ${ }^{21}$ However, tobacco consumption in younger between 20-29 years of age group was more prevalent in only one out of four provinces of Pakistan in our study. Meanwhile, study from China, Mexico and India have shown the highest smoking rates among younger age groups. ${ }^{19,22}$ In previous studies, tobacco smoking was associated with lower body weights. ${ }^{23}$ In our study, BMI was significantly higher in non-tobacco users and they were more obese compared to tobacco and ex-tobacco users, similar results were observed in related studies. ${ }^{24}$

Other contributory risk factors such as dysglycemia, dyslipidemia, and hypertension showed no significant association with tobacco and ex-tobacco use in our study similar to study of Khalid $\mathrm{N}$ et al., study that showed the $27 \%$ cigarette smokers with Type-II diabetes and Ain QU et al. study in which unhealthy relationship between hypertension and smoking was seen..$^{25,26}$ In our study, multiple logistic regressions showed that tobacco consumption was not associated with risk for dyslipidemia comparable to Yan-Ling $\mathrm{Z}$ et al., study. ${ }^{27}$ On the contrary, previous studies have also confirmed that heavy tobacco smoking is associated with increased total cholesterol and higher risk for abnormal total cholesterol in long-lived subjects. ${ }^{27}$

Use of tobacco mainly cigarette smoking is ever rising in Pakistan. ${ }^{21}$ Increased prevalence was due to accessibility and availability of tobacco that play a critical role in influencing adolescents to use tobacco. ${ }^{13}$ Still, we need to increase awareness programs and stronger implementation to stop tobacco advertisements, tobacco supply, banning free distribution of tobacco products, and events sponsored by tobacco companies, by doing this, we can control this hazard to a larger extent. ${ }^{26}$

Limitations of the study: Firstly, we lack data regarding tobacco consumption in subjects $<20$ years of age group who were not assessed as the cutoff of second NDSP (2016-2017) survey was 20 years. Using a non-comprehensive questionnaire, we are missing smoking and smokeless data separately, smoking related risk factors like peer pressure, witness violence at home, addiction, psychological problems, etc. and also complete tobacco related risk factors details from participants that are established in literature is another limitation.

Strengths of the study: Strength of our study is provision of age standardized data on prevalence of tobacco and ex-tobacco use in urban and rural population with its contributory biochemical risk factors in this part of the world in a proper epidemiological survey setting.

\section{CONCLUSION}

The prevalence of tobacco use is high. As a sub paper of a large national survey, this evidence is expected to serve as an important tool to plan larger studies leading in turn to develop strategies for a successful tobacco control program in the country.

Acknowledgements: We acknowledge the support of Research and Laboratory department of Baqai Institute of Diabetology and Endocrinology (BIDE), Karachi for data management and we would also like to thank Mr. Abdul Rashid and Mr. Muhammad Sohail from Pakistan Health Research Council (PHRC), Karachi. We are grateful to all study subjects for their participation in the 2nd NDSP.

* Co-Investigators - NDSP members (with surnames in alphabetical order):

* Dr. Mujeeb Ur Rehman Abro, Assistant Professor of Medicine, Chandka Medical College, Shaheed Mohtarma Benazir Bhutto Medical University, Larkana, Sindh, Pakistan.

* Dr. Khawaja Ishfaq Ahmed, Ex-PGR, Pakistan Institute of Medical Sciences, Islamabad, Punjab, Pakistan.

* Dr. Khurshid Ahmed, Consultant Physician, Zahid Medical Centre, Hub, Baluchistan, Pakistan.

* Dr. Sobia Sabir Ali, Assistant Professor, Department of Diabetes and Endocrinology, Lady Reading Hospital, Peshawar, Khyber Pakhtunkhwa, Pakistan.

* Prof. Ahmed Bilal, Professor and Head of Medical Department, Faisalabad Medical College, Faisalabad, Punjab, Pakistan.

* Dr. Anam Butt, Research Officer, Baqai Institute of Diabetology and Endocrinology, Baqai Medical University, Karachi, Sindh, Pakistan. 
* Prof. Bikha Ram Devrajani, Chairman, Department of Medicine and Director, Sindh Institute of Endocrinology and Diabetes, Liaquat University of Medical and Health Sciences, Jamshoro, Sindh, Pakistan.

* Mr. Ijaz Hayder, Research Officer, Pakistan Health Research Council, Karachi, Sindh, Pakistan.

* Dr. Yasir Humayun, EPI Coordinator, DHO Office, Mansehra, Khyber Pakhtunkhwa, Pakistan.

* Mrs. Rabia Irshad, Research Officer, Pakistan Health Research Council, Karachi, Sindh, Pakistan.

* Dr. Riasat Ali Khan, Diabetologist, Canada Medical Group Hospital, Defence, Karachi, Sindh, Pakistan.

* Dr. Asima Khan, Head of Diabetes Department, Sindh Government Hospital, New Karachi, Karachi, Sindh, Pakistan.

* Dr. Aamir Akram Khowaja, Postgraduate Resident, Sindh Government Qatar Hospital, Karachi, Sindh, Pakistan.

* Dr. Raheela Khowaja, Postgraduate Resident, Baqai Institute of Diabetology and Endocrinology, Baqai Medical University, Karachi, Sindh, Pakistan.

* Prof. Qazi Masroor, Professor of Medicine and Head of Department, Quaid-e-Azam Medical College, Bahawalpur, Punjab, Pakistan.

* Dr. Maqsood Mehmood, Head of Department, Fatma tu Zahra Hospital, Gujranwala, Punjab, Pakistan.

* Mr. Hassan Moin, Statistician, Baqai Institute of Diabetology and Endocrinology, Baqai Medical University, Karachi, Sindh, Pakistan.

* Ms. Nida Mustafa, Statistician, Baqai Institute of Diabetology and Endocrinology, Baqai Medical University, Karachi, Sindh, Pakistan.

* Dr. Wasif Noor, Diabetologist, Akhuwat Health Services Diabetes Centre, Lahore, Punjab, Pakistan.

* Dr. Huma Qureshi, Ex-Director, Pakistan Health Research Council, Islamabad, Punjab, Pakistan.

* Mr. Ibrar Rafique, Research Officer, Pakistan Health Research Council, Islamabad, Punjab, Pakistan.

* Dr. Tahir Rasool, Diabetologist, Akhuwat Health Services Diabetes Centre, Lahore, Punjab, Pakistan.

* Mrs. Rubina Sabir, Laboratory Manager, Baqai Institute of Diabetology and Endocrinology, Baqai Medical University, Karachi, Sindh, Pakistan.
* Dr. M. Arif N. Saqib, Senior Research Officer, Pakistan Health Research Council, Islamabad, Punjab, Pakistan.

* Dr. Pir Alam Said, Medical Specialist DHQ, Sawabi, Khyber Pakhtunkhwa, Pakistan.

* Prof. Abrar Shaikh, Head of Department of Medicine, Ghulam Muhammad Mahar Medical College, Sukkur, Sindh, Pakistan.

* Prof. AS Shera, Secretary General, Diabetic Association of Pakistan and WHO Collaborating Centre, Karachi, Sindh, Pakistan.

* Mr. Bilal Tahir, NDSP Coordinator, Baqai Institute of Diabetology and Endocrinology, Baqai Medical University, Karachi, Sindh, Pakistan.

* Prof. Salma Tanveer, Professor of Medicine, Incharge Diabetes and Endocrinology, Nishter Medical University, Multan, Punjab, Pakistan.

* Prof. Jamal Zafar, Professor of Medicine, Pakistan Institute of Medical Sciences, Islamabad, Punjab, Pakistan.

Disclosure of potential conflicts of interest: All authors declare that they have no conflict of interest.

Funding: $\mathrm{HbA1cs}$ and lipid profiles were performed by Pakistan Health Research Council (PHRC). Field visits and data collection including clinical and anthropometry measurements and also fasting plasma glucose and $2 \mathrm{hrs}$ post-glucose load samples were run by the respective teams through their own funds. The whole survey was coordinated and supported by the Baqai Institute of Diabetology \& Endocrinology (BIDE) on their own resources.

\section{REFERENCES}

1. WHO | Tobacco - World Health Organization. Available at: www.who.int/topics/tobacco/en. (Last accessed on 30-8-2018).

2. Mohan P, Lando HA, Panneer S. Assessment of tobacco consumption and control in India. Indian J Clini Med. 2018;9:1-8. doi: 10.1177/1179916118759289

3. Prevalence | Tobacco Atlas. Available at: https:// tobaccoatlas.org > topic > prevalence. (Last accessed on 4-9-2018).

4. World No Tobacco Day: Tobacco and Heart Disease Available at: https://www.who.int > Newsroom > Detail. (Last accessed on 4-9-2018).

5. Hossain S, Hossain S, Ahmed F, Islam R, Sikder T, Rahman A. Prevalence of tobacco smoking and factors associated with the initiation of smoking among university students in Dhaka, Bangladesh. Cent Asian J Glob Health. 2017;6(1):244. doi: 10.5195/cajgh.2017.244

6. Saqib MA, Rafique I, Qureshi H, Munir MA, Bashir R, Arif BW, et al. Burden of Tobacco in Pakistan: Findings from Global Adult Tobacco Survey 2014. Nicotine Tob Res. 2017;20(9):1138-1143. doi: 10.1093/ntr/ntx179 
7. Bonnie RJ, Kwan LY, Stratton KR. Committee on the Public Health Implications of Raising the Minimum Age for Purchasing Tobacco Products. Public health implications of raising the minimum age of legal access to tobacco products. Institute of Medicine (US). Washington, DC: National Academies Press. 2015:1-399.

8. Islam SM, Mainuddin AK, Chowdhury KN. Prevalence of tobacco use and its contributing factors among adolescents in Bangladesh. Heart India. 2016;4(3):85. doi: 10.4103/2321449x.190727

9. Rerksuppaphol L, Rerksuppaphol S. Prevalence of Cigarette Smoking and Associated Risk Factors amongst MiddleSchool Students in Ongkharak District, Thailand. J Med Assoc Thai. 2015;98(9):1-8.

10. WHO Framework Convention on Tobacco Control. Available at: http://www.who.int/ fctc/en. (Last accessed at 15-9-2018)

11. Khan JA, Sohail AM, Maan MA. Tobacco control laws in Pakistan and their implementation: A pilot study in Karachi. J Pak Med Assoc. 2016;66(7):875-879.

12. Basit A, Fawwad A, Qureshi H, Shera AS. Prevalence of diabetes, pre-diabetes and associated risk factors: Second National Diabetes Survey of Pakistan (NDSP), 2016-2017. BMJ Open. 2018;8(8):e020961. doi: 10.1136/ bmjopen-2017-020961

13. Grills NJ, Singh R, Singh R, Martin BC. Tobacco usage in Uttarakhand: A dangerous combination of high prevalence, widespread ignorance, and resistance to quitting. Bio Med Res Inter. 2015;2015:1-11. doi: 10.1155/2015/132120

14. Gilani SI, Leon DA. Prevalence and sociodemographic determinants of tobacco use among adults in Pakistan findings of a nationwide survey conducted in 2012. Popul Health Metr. 2013;11(1):16.

15. Palipudi K, Rizwan SA, Sinha DN, Andes LJ, Amarchand R, Krishnan A, et al. Prevalence and sociodemographic determinants of tobacco use in four countries of the World Health Organization: South-East Asia region: findings from the Global Adult Tobacco Survey. Indian J Cancer. 2014;51(5):24-32. doi: 10.4103/0019-509X.147446

16. Ngaruiya C, Abubakar H, Kiptui D, Kendagor A, Ntakuka MW, Nyakundi $\mathrm{P}$, et al. Tobacco use and its determinants in the 2015 Kenya WHO STEPS survey. BMC Public Health. 2018;18(3):1223.

17. Zafar M. Prevalence of smoking and associated risk factors among medical professionals in hospitals of Karachi, Pakistan. Int J Prev Med. 2014;5(4):457-462.

18. Sharifi H, Sadr M, Emami H, Ghanei M, Eslaminejad A Radmand G, et al. Prevalence of tobacco use and associated factors in Tehran: Burden of Obstructive Lung Disease study. Lung India. 2017;34(3):225-231. doi: 10.4103/09702113.205323.

19. Jawadi A. Smoking habit among Mosul medical students. Jordan Med J. 1984;18:79-89.

20. Sieminska A, Jassem E. The many faces of tobacco use among women. Med Sci Monit. 2014;20:153-162. doi: 10.12659/MSM.889796

21. Sinha DN, Rizwan SA, Aryal KK, Karki KB, Zaman MM, Gupta PC. Trends of smokeless tobacco use among adults (aged 15-49 years) in Bangladesh, India and Nepal. Asian Pac J Cancer Prev. 2015;16(15):6561-6568. doi: 10.7314/ apjcp.2015.16.15.6561

22. Singh A, Ladusingh L. Prevalence and determinants of tobacco use in India: Evidence from recent global adult tobacco survey data. PLoS One. 2014;9(12):e114073. doi: 10.1371/journal.pone.0114073
23. Flegal KM. The effects of changes in smoking prevalence on obesity prevalence in the United States. Am J Public Health. 2007;97(8):1510-1514. doi: 10.2105/ AJPH.2005.084343

24. Dare S, Mackay DF, Pell JP. Correction: Relationship between smoking and obesity: A cross-sectional study of 499,504 middle-aged adults in the UK general population. PloS One. 2017;12(2):e0172076. doi: 10.1371/journal. pone. 0172076

25. Khalid N, Khan EA, Saleem S, Tahir A, Mahmood H, Saleem S. Prevalence and associated factors of cigarette smoking among Type-II Diabetes Patients in Pakistan. Int J Collab Res Intern Med Public Health. 2014;6(4):73.

26. Ain QU, Regmi K. The effects of smoking in developing hypertension in Pakistan: a systematic review. South East Asia J Public Health. 2015;5(1):4-11. doi: 10.3329/seajph. v5i1.24845

27. Yan-Ling Z, Dong-Qing Z, Chang-Quan H, Bi-Rong D. Cigarette smoking and its association with serum lipid/lipoprotein among Chinese nonagenarians/ centenarians. Lipid Health Disea. 2012;11(1):94. doi: 10.1186/1476-511X-11-94

\section{Authors' Contributions:}

AB: Concept, design, interpretation of data, edited and approved the manuscript.

BBY: Concept, design and involved in the quality control.

NW: Literature search, interpretation of data, wrote the manuscript.

AF: Concept, design, interpretation of data, edited and approved the manuscript.

NDSP Members: Members were responsible for the supervision of the survey, concept, design, involved in the quality control, data management in their respective areas and responsible for accuracy or integrity of the work. All members approved the final submitted version.

Authors:

1. Abdul Basit, FRCP.

Professor of Medicine (BMU), Director (BIDE),

2. Bilal Bin Younus, FRCP.

Professor of Medicine,

Principal and Associate Dean Academics (FMMDC), Fatima Memorial Medical and Dental College,

Lahore, Punjab, Pakistan.

3. Nazish Waris, M.Phil.

Clinical Biochemistry and Psychopharmacology Research Unit Department of Biochemistry, University of Karachi, Pakistan. Research Associate, Research Department (BIDE-BMU),

4. Asher Fawwad, PhD.

Professor \& Head of the Biochemistry Department (BMU), Honorary Research Director (BIDE),

* NDSP Members,

1,3,4: Baqai Institute of Diabetology and Endocrinology (BIDE), Baqai Medical University (BMU), Karachi, Sindh, Pakistan. 